\title{
Immunohistochemical Studies on the Processes of Serotonin Neurons and their Ramification in the Central Nervous System - with Regard to the Possibility of the Existence of GoLGI's Rete Nervosa Diffusa*
}

\author{
Yutaka Sano, Yoshihiro Takeuchi, ${ }^{1}$ Hiroshi Kimura, ${ }^{2}$ Motoko Goto, \\ Mitsuhiro Kawata, Munekado Kojima, Tadao Matsuura, \\ Shuichi UEDA and Hisao YAMADA ${ }^{1}$ \\ Department of Anatomy (Prof. Y. Sano), ${ }^{1}$ Kyoto Prefectural University of Medicine, Kyoto, and \\ Department of Anatomy, ${ }^{2}$ Shiga University of Medical Science, Otsu, Japan
}

Received June 14, 1982

Summary. Using various vertebrates from teleost to macacus, we studied, by the modified PAP method, the serotonin neurons that are distributed mainly in the raphe nuclei area, focussing on their process ramifications, and obtained the following results.

1. The shapes of serotonin neurons were varied. They were multipolar with many long, thick dendrites. In most of the neurons, more than two axons originated either from the stem of a dendrite or from its tip.

2. The axons contained spherical or spindle-shaped varicosities of varied sizes (diameter 0.5-6 $\mu \mathrm{m}$ ). On a few occasions, they became large, Herring body-like droplets.

3. The axons were classified into four groups according to the shape and size of the varicosities they contained: stem fibers, A-fibers (tract fibers), B-fibers (branching fibers) and C-fibers (ground fibers).

4. The axon not only branched frequently, but formed a true network by way of frequent anastomosis at the level of B- and C-fibers. Serotonin fibers do not have endings that correspond to telodendrons, but conduct impulses through "en passant" type synapses.

5. A supraependymal plexus is formed over large areas of the ventricular system. This vast network is considered to be formed by the syncytial continuity of axonal reticulum of many serotonin neurons.

6. Serotonin neurons, and probably noradrenalin neurons as well, should be classified as a third type of neuron, which belong to neither the Deiters type nor the Golgi type neuron. Their characteristic feature is the long, reticular axons, and it is highly probable that this neuron system forms the "rete nervosa diffusa" proposed by GoLGI.

In 1978, STEINBusch and his co-workers succeeded in obtaining highly specific serotonin antiserum by immunizing rabbits with serotonin coupled with bovine serum albumin * This work was supported by a grant (No. 57214028) from the Ministry of Education, Science and Culture, Japan. 
as the antigen. Independently from the STEInBusch group, we have obtained serotonin antiserum of very high specificity and sensitivity by immunizing rabbits with serotonin coupled with bovine thyroglobulin (TAKEUCH et al., 1982).

Using their antiserum for immunofluorescence histochemical study, STEINBusch and associates have published several outstanding papers on the distribution of serotonin neurons and their processes in the central nervous system of the rat (STEINBUSCH and Verhofstad, 1979; Steinbusch, 1981; KöHler et al., 1981). KöHler and his coworkers classified the serotonin fibers distributed in the retrohippocampal region of the rat into four different types according to their structural characteristics.

By applying our new antiserum to the peroxidase-antiperoxidase technique (PAP; STERNBERGER, 1974), we succeeded in obtaining results much more stable and detailed than those obtained by the immunofluorescence method. We studied the central nervous system of various vertebrates, and found that axons of serotonin neurons not only branch out also anastomose frequently to form vast networks of varicose fibers.

In the present study we shall report on the characteristic morphological features of axonal branches and anastomoses in the serotonergic neuron system and discuss the functional significance of the axonal reticulum, thus formed.

\section{MATERIALS AND METHODS}

For immunohistochemical staining, monkeys, cats, rats, domestic chickens and carp were used. Under Nembutal anesthesia, the animals were perfused via the left ventricle with phosphate-buffered saline (PBS) followed by a solution of $4 \%$ paraformaldehyde (FA), $0.2 \%$ picric acid (PA) and $0.4 \%$ glutaraldehyde (GA) in $0.1 \mathrm{M} \mathrm{PB}$ at $4{ }^{\circ} \mathrm{C}$. The brain was immersed in this fixative minus GA for $48 \mathrm{hrs}$ and cut into $20 \mu \mathrm{m}$ sections on a cryostat and then processed by a modified PAP immunohistochemical method.

The immunohistochemical staining was accomplished with free-floating sections by sequential application of 1 ) rabbit serotonin antiserum $(1: 32,000)$ for $24 \mathrm{hrs}, 2)$ goat anti-rabbit IgG (Miles-Yeda Ltd., 1:200) for $3 \mathrm{hrs,} \mathrm{3)} \mathrm{peroxidase-antiperoxidase} \mathrm{(Dako.}$ Co., 1:200) for $90 \mathrm{~min}$, 4) 3, 3'-diaminobenzidine (Sigma) containing $\mathrm{H}_{2} \mathrm{O}_{2}$ for 10 min and 5) osmium tetraoxide $(0.05 \%)$ for $10 \mathrm{~min}$. Following these immunohistochemical procedures, the sections were counterstained.

(For details of the preparation and specificity of the antiserum, see TAKEUCHI et al., 1982).

\section{RESULTS}

In all of the materials used in this study, the cell bodies of the serotonin neurons were localized in the brainstem. In mammals, they occupied large parts of the nucleus raphe pallidus (B1), nucleus raphe obsculus (B2), nucleus raphe magnus (B3), nucleus reticularis (B3), nucleus raphe pontis (B5), nucleus raphe dorsalis (B7), nucleus centralis superior (B8; nucleus raphe medianus) and the area around the lemniscus medialis (B9), and were also present in the nucleus interpeduncularis and periaqueductal gray matter. In birds and lower vertebrates, serotonin neurons were found as liquidcontacting neurons in the periventricular organs and infundibular organs. So far no serotonin-containing cell bodies have been found at any place within the ventricles.

The sizes of the cell bodies of serotonin neurons were variable. In the nucleus 

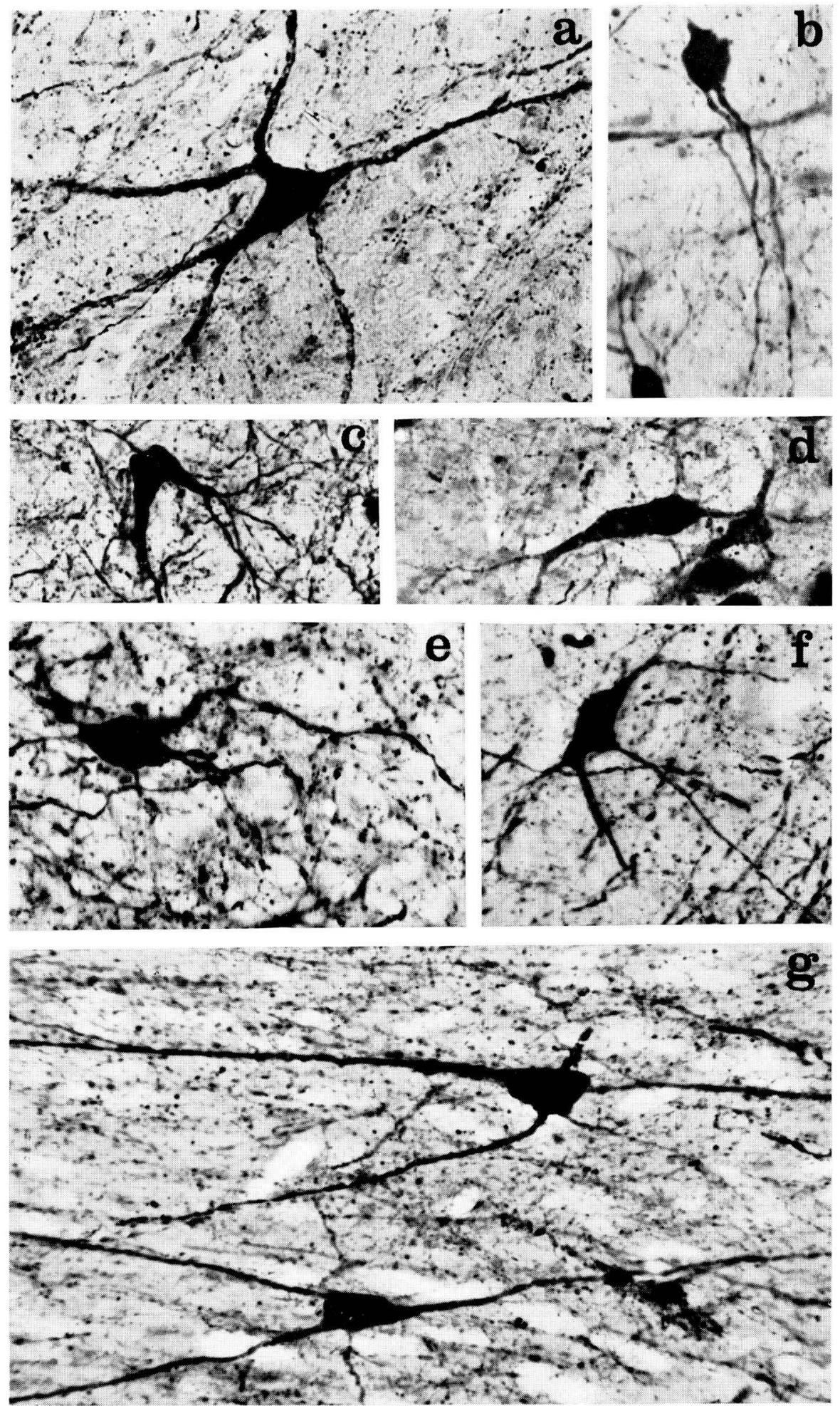

Fig. 1. Serotonin neurons of various shapes in the reticular formation. $\mathbf{a}-\mathbf{f}$ : monkey, $\times 250$. g: rat, $\times 400$ 
interpeduncularis and raphe pallidus, relatively small neurons (ca. $20 \mu \mathrm{m} \times 15 \mu \mathrm{m}$ ) predominated while exceptionally large neurons (ca. $40 \mu \mathrm{m} \times 20 \mu \mathrm{m}$ ) were found sporadically in the rostral or lateral parts of the nucleus raphe dorsalis. Serotonin neurons were multipolar, and because of the differences in the number of dendrites and the mode of their origin, they presented varied appearances: spindle-shaped, stellar, pyramidal, round and bizarre shapes (Fig. 1).

The directions in which the dendrites projected were also variable. Sometimes they projected radially in a stellar shape, and sometimes they extended in two opposite directions from the ends of spindle-shaped cell bodies. Sometimes several dendrites extended from one end of a cell body, giving it the look of an octopus. In such cases, that side of the cell body often bulged out in a piriform or ameboid way. The dendrites were thick and often long and straight, like rods, especially in the larger serotonin neurons. It was sometimes possible to trace one as long as $800 \mu \mathrm{m}$. Such thick dendrites very often continued long distances without changing their calibers and usually did not arborize near the cell bodies. They seemed to be smooth-surfaced without spines, showing no varicosities (Fig. $1 \mathrm{~g}$ ).

Axons could be identified because they were thin and varicose. At times they originated directly from the cell bodies, and other times from the proximal part of thick dendrites. It was particularly interesting to find that sometimes an axon, or even several branching axons, with varicosities, were observed to originate from the tip of a rod-shaped denrite several hundred micrometers long.

Axon stems often ran straight toward their destinations. Typical specimens of such axons were seen in the funiculus lateralis of the spinal cord, the gyrus cinguli,

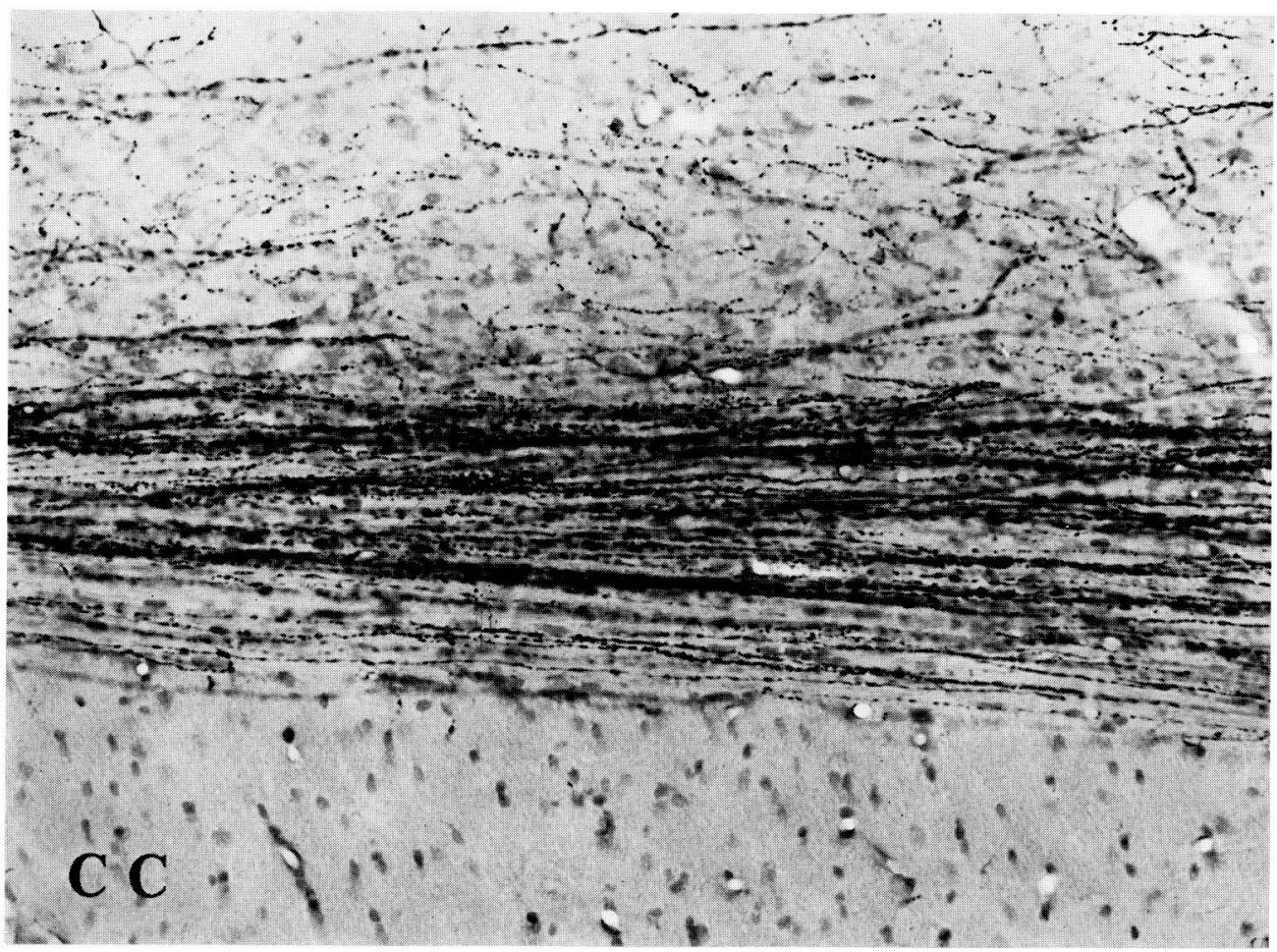

Fig. 2. Cingulum bundle of serotonergic tract-fibers in the rat. $C C$ corpus callosum. $\times 250$ 
the tegmentum mesencephali and the medial forebrain bundle (Fig. 2). Serotonin fibers usually did not form such compact, distinct tracts as did the pyramidal tract or fasciculus longitudinalis medialis. Those fibers that originated from the raphe dorsalis and ascended through the tegmentum mesencephali were more compact than others, but they were still much more loosely formed as compared to the non-serotonergic tracts. As a rule, axons and their branches were varicose fibers. The diameter of varicosities usually measured $0.5-6 \mu \mathrm{m}$. Occasionally, large Herring's body-like varicosities over $10 \mu \mathrm{m}$ in diameter were observed in the ventrolateral funiculus in the lumbosacral part of the spinal cord. They were probably caused by interruption in the axonal flow.

Intervaricose segments were thin, and often did not show a positive PAP reaction, giving the varicosities the look of separate dots. Therefore it is not feasible to discuss the diameter of serotonin fibers of varicose segments.

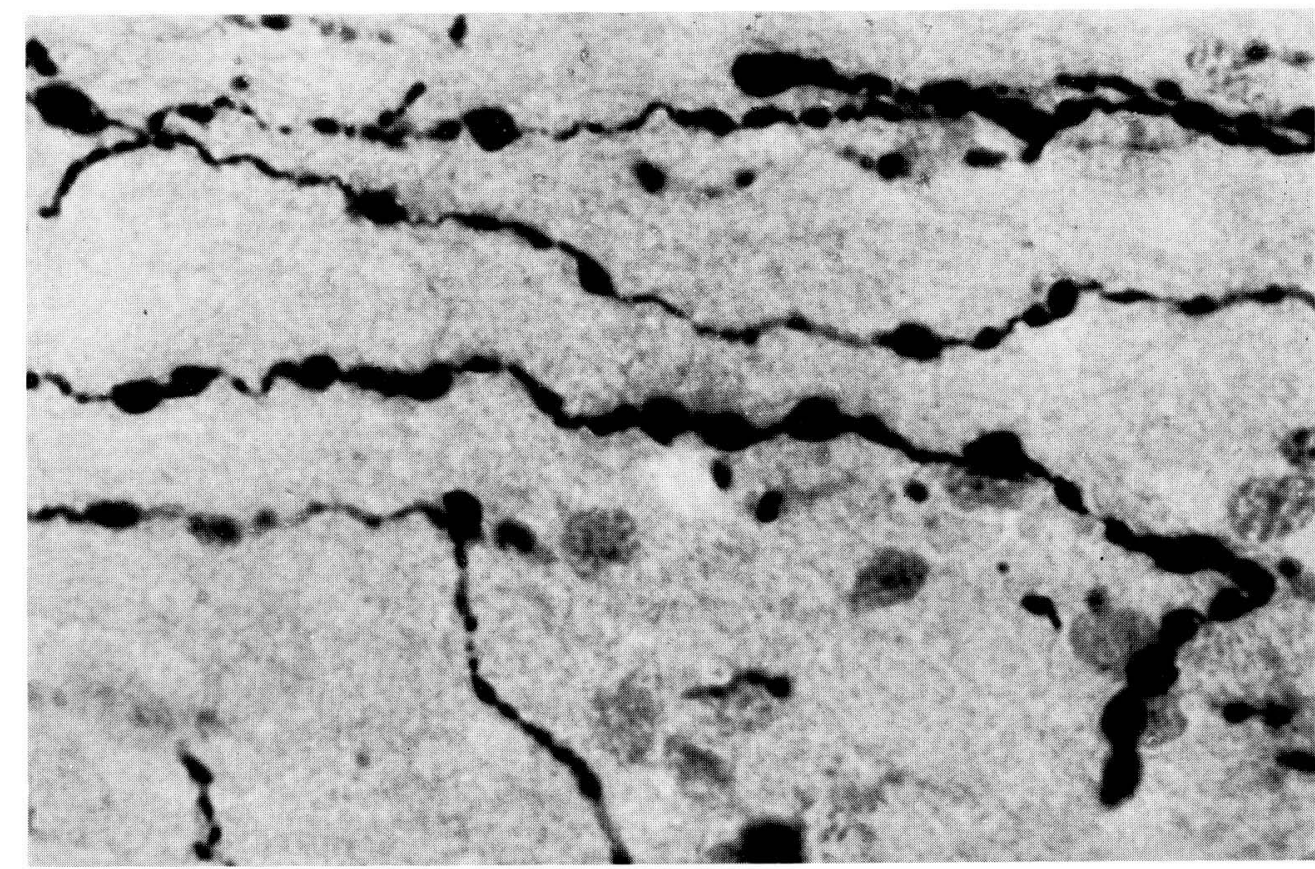

Fig. 4. Tract-fibers (A-fibers) with large varicosities of $4-5 \mu \mathrm{m}$ diameter in the lateral funiculus of the dog spinal cord. $\times 1,250$

\section{stem fiber}

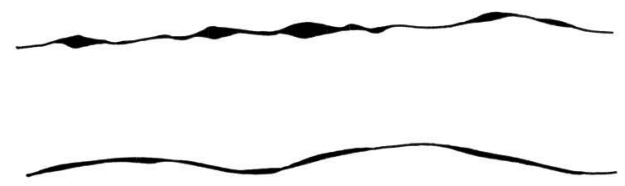

A-fiber

B-fiber

C-fiber

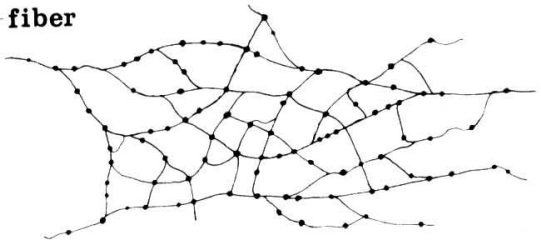

Fig. 3. Diagram showing the processes of serotonin neurons as classified into four groups (stem, A-, B- and C-fibers). 
Although the sizes and shapes of varicosities and the distances between them were not uniform when observed in a PAP specimen, there were sufficient similarities to warrant the classification of the fibers into groups based on the characteristics of their varicosities (Fig. 3).

The stem fibers originated from cell bodies, were thick, and their varicosities were diamond-shaped and spaced at fairly regular intervals. The stem fibers branched into either $A$-fibers (tract fibers) with varicosities of $4-5 \mu \mathrm{m}$ diameter or $B$-fibers (branching fibers) with varicosities of $2-3 \mu \mathrm{m}$ diameter (Fig. 4). B-fibers were originated from Afibers or directly from the stem fibers. In A- and B-fibers, varicosities were often so close together that they took the appearance of pearl necklaces. Varicosities were usually spherical, but sometimes they appeared in various irregular shapes. When many varicosities were fused to form long rod-like shapes, they could be mistaken for thick, smooth fibers.

A- and B-fibers further branched off to form very thin C-fibers (ground fibers) which had small varicosities $0.5-1 \mu \mathrm{m}$ in diameter. C-fibers were considered to be the terminal part of a serotonin fiber, and they had a fine, hair-like appearance when they did not contain varicosities.

Fibers ascending from the raphe nuclei, especially the dorsal raphe nuclei, ran toward the ventral portion of the tegmentum mesencephali and then to the diencephalon. The serotonin bundles, which consisted of stem fibers, did not mingle with the thick bundles of the pyramidal tract. There were frequent exchanges of fibers between the two serotonin bundles, just like those of the plexus of the spinal nerves, before they ascended to form the tegmental tract (Fig. 5).

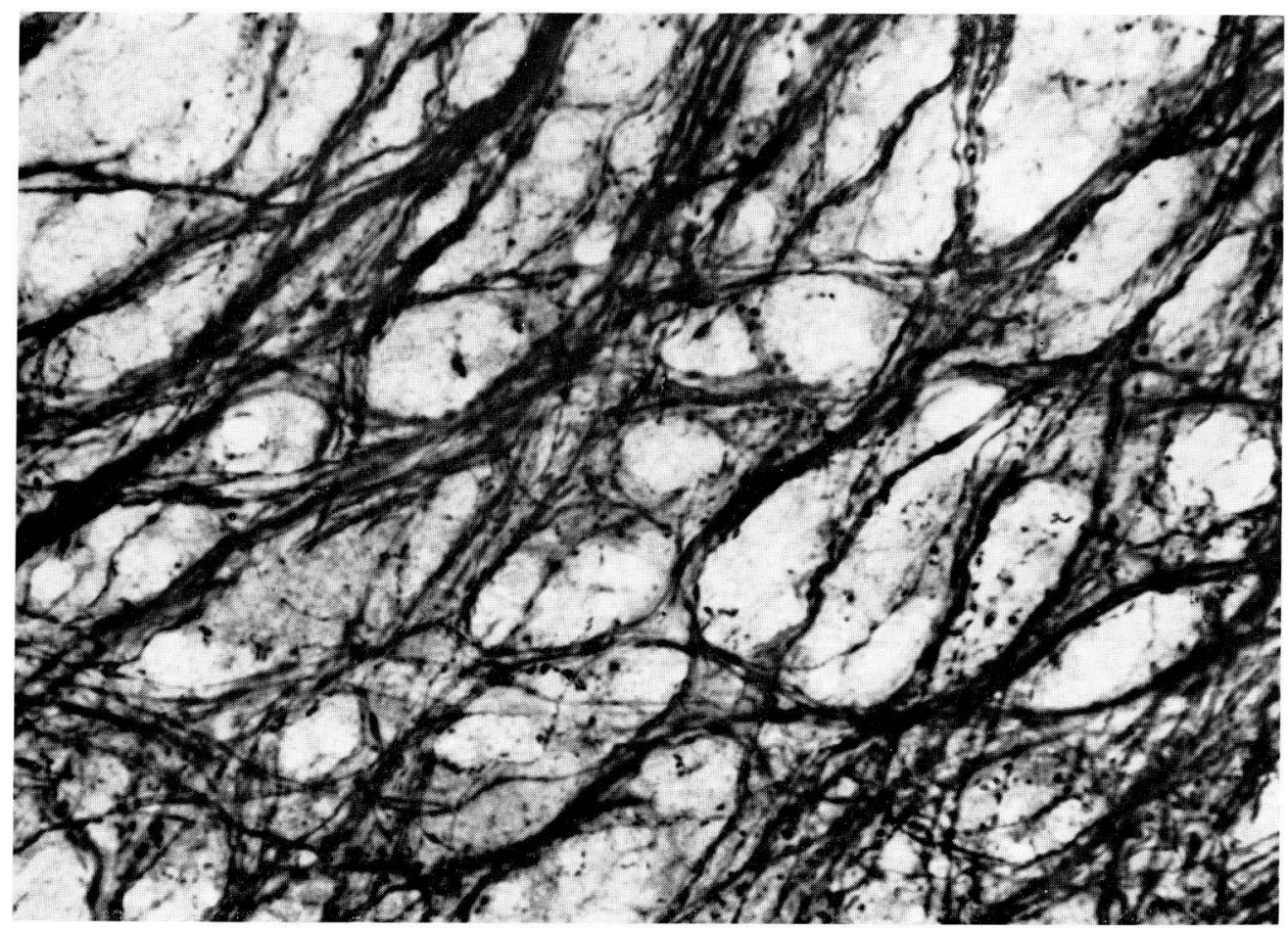

Fig. 5. Plexus of serotonergic bundles composed of stem fibers in the ventral tegmentum of the cat. The bundles are intertwined with myelinated fasciculi (fibrae pontis longitudinales). $\times 250$ 


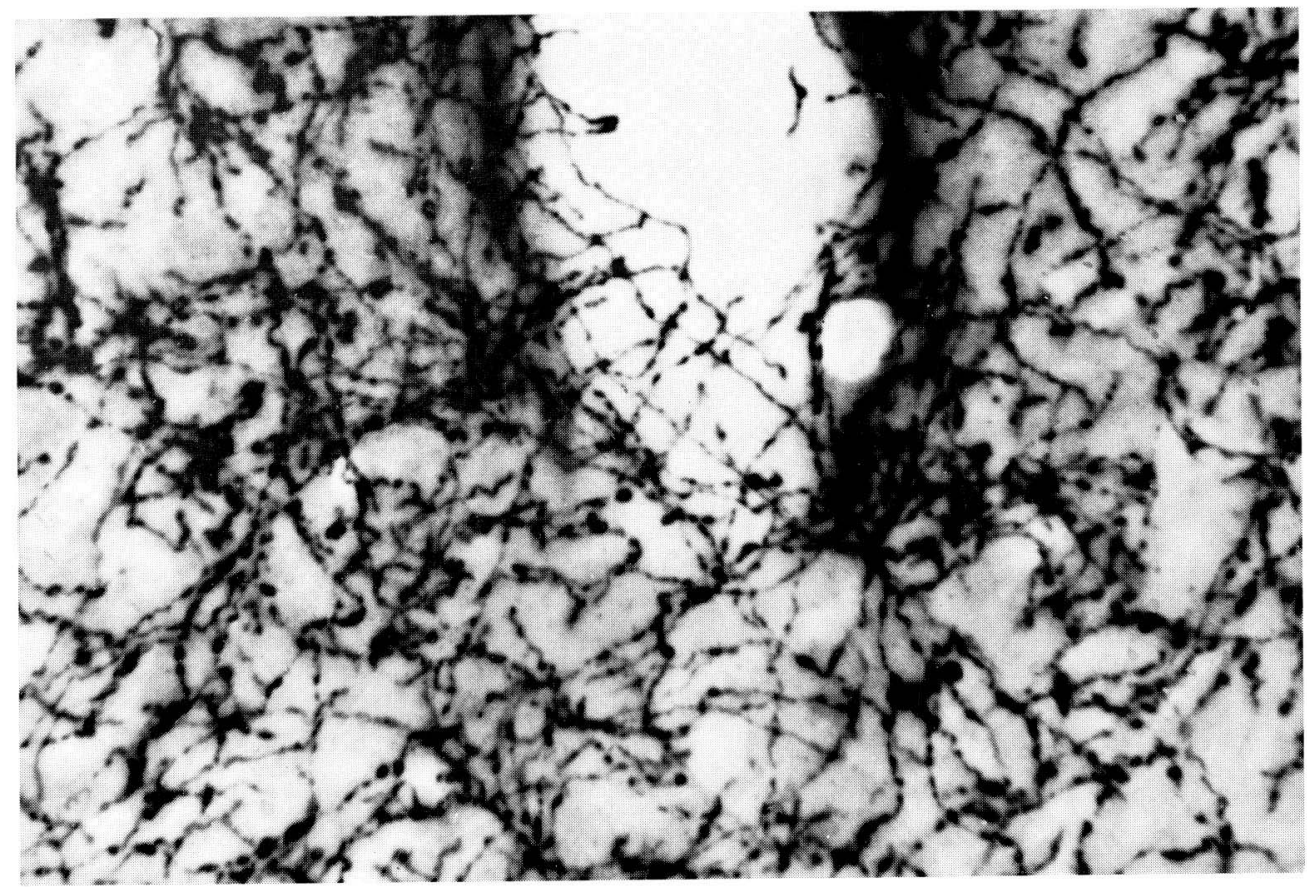

Fig. 6. Serotonin fiber network in the inferior colliculus of the cat. Note a laticework of C-fibers in the tangential section of the wall of a large vessel. $\times 700$

A-, B- and C-fibers all branched off and anastomosed frequently. Sometimes the size of the varicosities was smaller after branching, but very often the fibers retained their characteristics even after branching. This was particularly evident in C-fibers, which branched and anastomosed without changing their diameters to form a network of uniform fibers.

As the above description shows, serotonin fibers did not simply arborize but formed a true network by frequent anastomosis.

The reticular structure of serotonin fibers was extended three-dimensionally and was difficult to realize in thin, microscopic sections. In the white matter, especially in the tracts consisting of myelinated fibers and in the optical nerves, the serotonin fibers did not form a network. In the grey matter, however, serotonin fibers were observed forming networks without exception and anastomoses

Fig. 7. Diagram showing the entire shape of serotonin neuron forming a true network by way of frequent anastomoses.

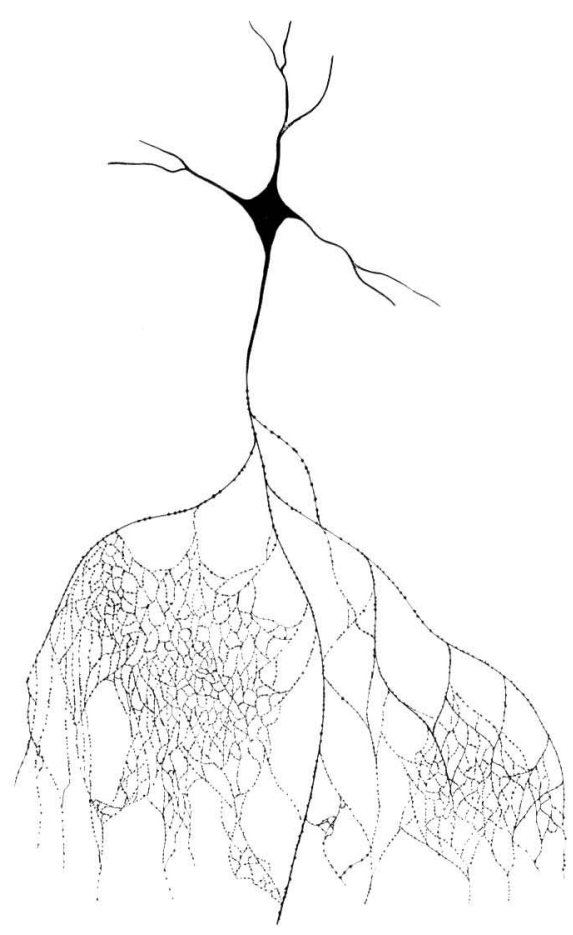




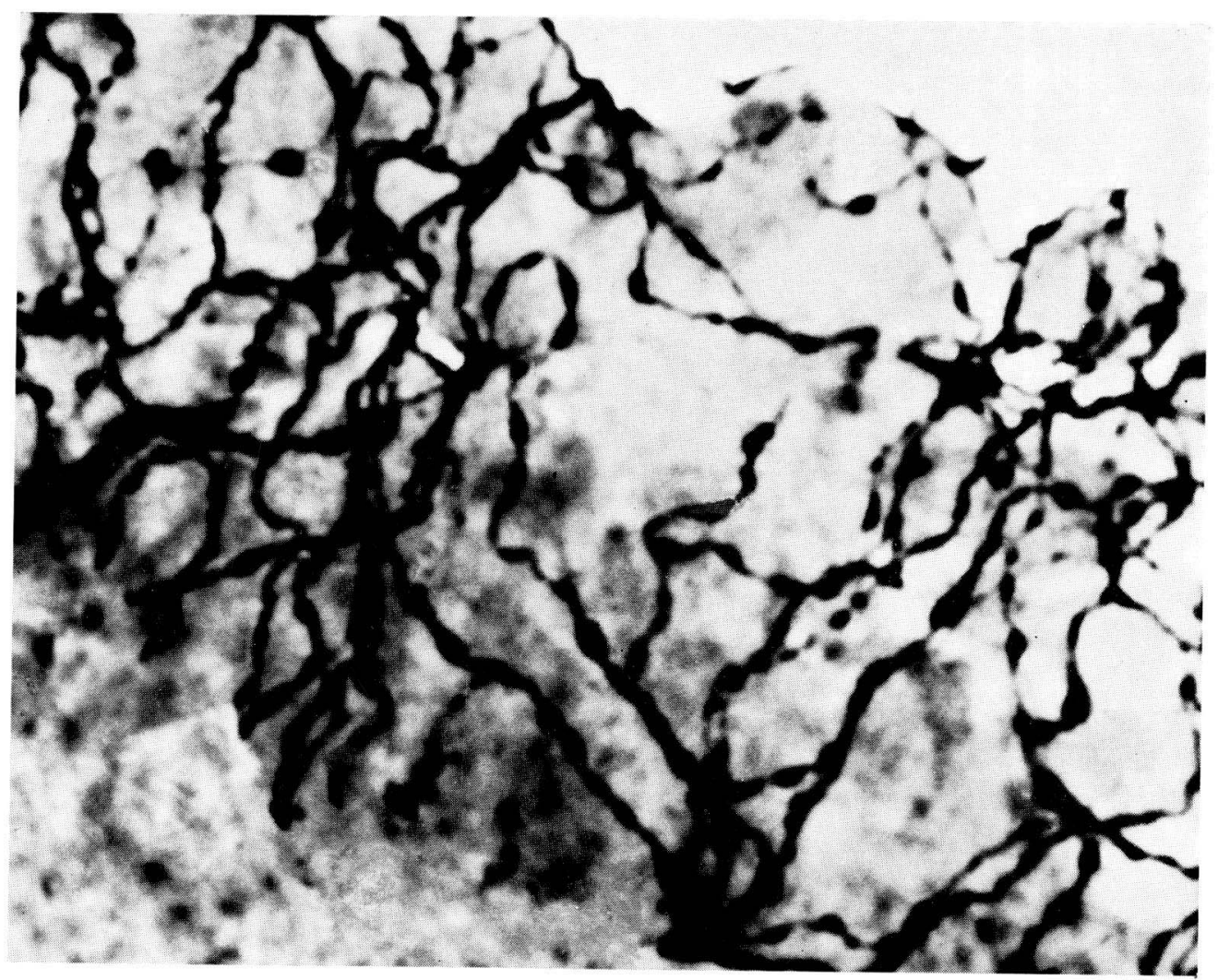

Fig. 8. Supraependymal plexus of 5 -HT fibers in the third ventricle of the rat. $\times 1,400$

occurred constantly. Serotonin fiber networks were particularly evident in those parts where there was abundant serotonin innervation, such as the hippocampus, corpus geniculatum laterale, corpora quadrigemina and columna anterior. A latticework of the C-fibers was easily observed in the tangential sections of the walls of large vessels (Fig. 6).

Based on these observations, we at first concluded that an axon from a serotonin neuron, by arborization and anastomosis with its own branches, takes the form shown in Figure 7. However, examination of the supraependymal serotonin plexus suggested the possibility of anastomosis between axons from different serotonin neurons, resulting in syncytial protoplasmic continuity.

In PAP specimens, serotonin fibers penetrated the ependymal cell layer at various parts of the ventricular walls and formed a network spreading over the ventricular surface (Fig. 8).

Particularly dense supraependymal plexus could be observed at various parts of the ventricular wall from the ventriculus lateralis to the ventriculus quartus (details to be published later). In such parts, the fibers ran along the border of each ependymal cell, in the manner of terminal bars, forming a net with its openings corresponding in size to the ependymal cells, which was about $18 \mu \mathrm{m}$ in diameter. Even thicker fibers, probably stem fibers, were observed among the fibers that constituted supraependymal plexus, and their branches formed a delicate network. They spread further without interruptions, so it was impossible to determine whether a certain area of this network 
was supplied with axons from a single neuron, or whether it received an overlapping supply of axons. It was more reasonable to assume that branches of the axons of an undetermined number of serotonin neurons communicated with each other to form a syncytial network along the large ventricular surface.

The fibers that constituted the network of the supraependymal plexus were varicose fibers, and very often the points of branching in the net coincided with a varicosity. The number of varicosities surrounding one opening of the net was varied. Scanning electron microscope observation of the ventricular walls showed a network of varicose fibers, which in all probability was the serotonin network. The fibers were unmyelinated and varicose, and they branched off from the nodules. As mentioned earlier, no serotonin cell body was found in any part of the ventricular wall. Therefore, we must conclude that the serotonin fibers that formed the intraventricular plexus are all derived from the serotonin cell bodies in the raphe nuclei.

\section{DISCUSSION}

Establishment of the formaldehyde-induced fluorescence (FIF) histochemistry by FALCK et al. (1962) made detailed morphological studies of serotonin neurons possible, and based on the optical features of maximal excitation and emission spectra and changes after treatment with chemicals, the distribution of and communications between serotonin fibers were clarified to some degree (DAHLSTRÖM and FuXE, 1964). Ever since, many new methods, such as the improved FIF technique, pretreatment with false transmitters, autoradiography using ${ }^{3} \mathrm{H}$-serotonin and immunohistochemistry of tryptophan hydroxylase, have been employed to further our knowledge of serotonin neurons. It was, however, the establishment and application by STEINBUSCH and others in 1978, of the immunofluorescence technique using serotonin antiserum, which greatly advanced the study of the serotonin neuron system.

We have, independently from STEINBUSCH, raised a rabbit antiserotonin antiserum, and its application to the PAP method enabled detailed observation of serotonin neurons and their processes in permanent specimens. With our method, serotonin neurons were selectively stained, looking like Golgi-stained neurons. The shape of the cell bodies and their processes were varied, as shown in Figure 1. One characteristic feature was that most of the large serotonin neurons possessed very long, straight dendrites that rarely branched. Axons often originated from the tips of long dendritic thick protoplasmic processes, and usually several axons originated from one cell body. These findings are in conflict with the established concepts of axons.

The subject which deserves the most attention and discussion in this paper is the anastomosis of serotonin fibers. As already described in the "Results" and shown in the figures and the schematic drawing, axons of serotonin neurons form a true network by frequent branching and anastomosis, in a manner completely different from simple arborization. Moreover, this network was not confined to the terminal branching of long axons, i.e., telodendrons, but was formed along the whole length of the axon, from the very root of the axon to the terminal. This fact convinced us that serotonin neurons take the shape shown in Figure. 7.

So far it has not been clarified how many numbers of serotonin neurons send descending fibers to the spinal cord, but the fibers were more densely distributed the more caudally they continued. This is a complete reverse of the fibers in the pyramidal tract, where their number decreases as they descend lower. Even this fact alone 
suggests that the mode of branching of serotonin fibers does not conform to the established concepts of the branching of nerve fibers.

Golgi studied each part of the central nervous system in detail (1890), using the reazione nera which he created himself, and found the Golgi type II cells with short axons. He believed that they maintained protoplasmic continuity with each other through their axonal branches, and that the rete nervosa diffuse was formed by their communication with the collaterals of Deiters type (Golgi type I) neurons.

This theory was violently opposed by CAJAL (1907), and it was completely rejected when the existence of the synaptic cleft was established by application of electron microscopy to biology. However, we should like to stress here that the absence of continuity at synapses and the existence of axonal anastomosis are not mutually exclusive.

Through electron microscopic study of monoamine neurons, it has been found that many of the numerous varicosities in the axons of these neurons are the sites of "en passant" type synapses. In serotonin neurons, the varicosities in their axons are considered to be depots of serotonin, and in B- and C-fibers in the grey matter, each varicosity probably acts as a synapse. Particularly large neurons, such as anterior horn motoneurons, are often seen surrounded by pearl-necklace-like varicose serotonin neurons. However, these varicose fibers do not terminate there as telodendrons, but leave these cell bodies and move on to other parts, with frequent branching and anastomosis along the way. Such observations indicated that the axons of serotonin neurons and their branches form the "rete nervosa diffusa" and, at the same time, at numerous varicosities, also form synapses by contiguity, not continuity. It seems thus most reasonable to conclude that the axons of the serotonin neuron actually form one endless network.

In fluorescence histochemistry of membranous tissues such as the mesenterium or iris, it has often been observed that the nerve fibers constituting a perivascular monoaminergic plexus form a network by frequent anastomosis and branching, and also that plexuses on the walls of two separate vessels are often connected with well developed nerve fibers. Moreover, as has been observed in cultures of various nerve cells by such researchers as Esaki (1929), Levi (1934), Costero and Pomerat (1951) and Hild (1954), and SANo et al. (1967) also, sympathetic postganglional neurons, when cultured, develop processes that formed networks. These facts suggest that, in non-myelinated fibers, or in cultures in which a glial sheath is not formed, neuronal axons anastomose easily. Since axons of noradrenaline- and serotonin-containing neurons are nonmyelinated, they probably have a natural inclination to form networks. We are currently investigating the formation of the axonal reticulum of the immature serotonin neurons in tissue cultures of mammalian raphe nuclei. As described in the "Results", bundles of stem fibers exchange fibers with each other in a manner resembling that of the spinal nerve plexus. This shows that, in the serotonin neuron system, the action of a mass of neurons, rather than that of individual neurons, is important.

So far the existence of a syncitial connection between serotonin neurons is not completely proven. However, considering the supraependymal plexus, the existence of the rete nervosa diffusa as proposed by GoLGI becomes increasingly plausible.

After the introduction of the electron microscope, many neuroanatomists have, mainly through impregnation findings, insisted on the existence of the continuity between neurons through neurofibrils. They claimed to have found various structures that seemed to refute the neuron theory, and gave them such names as Terminalreticulum (STÖHR, 1957), praeterminales Netzwerk (REISER, 1959), sympathetic ground 
plexus (Boeke 1949), and others. Their theories were neglected as they were based on the staining of neurofibrils, which turned out to be artifactitious structures. However, the existence of anastomosis between sympathetic fibers, which they observed so frequently, cannot be denied.

Neurons that constitute the central nervous system are varied in their shapes according to the parts they play. The Deiters type (Golgi type I) neurons, for example, are best suited for communicating nuclei or centers with each other. Conduction of impulses from a sensory organ (as in a lateral spinothalamic tract) or conduction for voluntary movement (pyramidal tract, for example) are representative functions of the tracts formed by the Deiters type neurons. The Golgi type neurons with short, branching axons, on the other hand, are best suited for the integration of various information received, and also for the formation of mental concepts.

The serotonin neurons we have observed in the present study do not belong to either the Deiters or the Golgi type. They have long axons like those of the Deiters neurons but their axons are highly ramified, even at the base, as in the Golgi neurons. Moreover, these branches form networks by anastomosis and there seems to be even the possibility of these neurons having syncitial continuity. These neurons, which must be classified as a third type of neuron, probably are related to numerous other neurons through en passant type synapses, and may exert their effect on those neurons en masse. It seems not unreasonable to postulate that the serotonin neuron system, together with the noradrenaline neuron system, works in the central nervous system as the controller of the level of the activities of the Deiters and Golgi type neuron systems.

\section{REFERENCES}

Boeke, J.: The sympathetic endformation, its synaptology, the interstitial cells, the periterminal network and its bearing on the neurone theory. Discussion and critique Acta anat. (Basel) 8: $18-61$ (1949).

Cajal, S. Ramon y: Die histologischen Beweise der Neuronentheorie von His und Forel. Anat. Anz. 30: 113-144 (1907).

Costero, J. and M. Pomerat: Cultivation of neurons from the adult human cerebral and cerebellar cortex. Amer. J. Anat. 89: 405-468 (1951).

Dahlström, A. and K. Fuxe: Evidence for the existence of monoamine-containing neurons in the central nervous system. I. Demonstration of monoamines in the cell bodies of brain stem neurons. Acta physiol. scand. 62 (Suppl. 232): 1-55 (1964).

Esaki, S.: A sure method for the elective staining of neuro-fibrillae in tissues cultivated in vitro. Z. wiss. Mikrosk. 46: 369-376 (1929).

Falck, B., N.-A. Hillarp, G. Thieme and A. Torp: Fluorescence of catecholamines and related compounds with formaldehyde. J. Histochem. Cytochem. 10: 348-354 (1962).

Golgi, C.: Über den feineren Bau des Rückenmarkes. Anat. Anz. 5: 372-396, 423-435 (1890).

Hild, W.: Das morphologische, kinetische und endokrinologische Verhalten von hypothalamischem und neurohypophysärem Gewebe in vitro. Z. Zellforsch. 40: 257-312 (1954).

Köhler, C., V. Chan-Palay and H. Steinbusch : The distribution and orientation of serotonin fibers in the entorhinal and other retrohippocampal areas. An immunohistochemical study with antiserotonin antibodies in the rat's brain. Anat. Embryol. 161: 237-264 (1981).

Levi, G.: Explantation, besonders die Struktur und die biologischen Eigenschaften der in vitro gezüchteten Zellen und Gewebe. Erg. Anat. Entw.-Gesch. 31: 125-707 (1934). 
Reiser, K. A.: Die Nervenzelle. In: Möllendorff-Bargmanns Handbuch der mikroskopischen Anatomie des Menschen. IV/4. Springer-Verlag, Berlin-Göttingen-Heidelberg, 1959 (p. 185-514).

Sano, Y., G. Odake and T. Yonezawa: Fluorescence microscopic observations of catecholamines in cultures of the sympathetic chains. Z. Zellforsch. 80: 345-352 (1967).

Steinbusch, H. W. M.: Distribution of serotonin-immunoreactivity in the central nervous system of the rat-Cell bodies and terminals. Neuroscience 6: 557-618 (1981).

Steinbusch, H. W. M. and A. A. J. Verhofstad: Immunofluorescent staining of serotonin in the central nervous system. In: (ed. by) P. Simon: Advances in Pharmacology and Therapeutics. Pergamon Press, Oxford, 1979 (Vol. 2, p. 811-819).

Steinbusch, H. W. M., A. A. J. Verhofstad and H. W. J. Joosten : Localization of serotonin in the central nervous system by immunohistochemistry: description of specific and sensitive technique and some applications. Neuroscience 3: 811-819 (1978).

Sternberger, L. A.: Immunohistochemistry. Prentice Hall, Englewoods Cliffs, New Jersey, 1974.

Stöhr, Ph., jr.: Mikroskopische Anatomie des vegetativen Nervensystems. In: MöllendorffBargmanns Handbuch der mikroskopishen Anatomie des Menschen. IV/5. Springer-Verlag, Berlin-Göttingen-Heibelberg, 1957.

Takeuchi, Y., H. Kimura and Y. Sano: Immunohistochemical demonstration of the distribution of serotonin neuron in the brainstem of the rat and cat. Cell Tiss. Res. 224: 247-267 (1982).

佐野 豊

干602 京都市上京区河原町通広小路

京都府立医科大学

第一解剖学教室
Prof. Yutaka SANo

Department of Anatomy

Kyoto Prefectural University of Medicine

Kawaramachi-Hirokoji

Kyoto, 602 Japan 